\title{
É possível falarmos em “desindustrialização” no Paraná?
}

\author{
Marcio José V argas da Crur*
} Luciano Nakabashi ${ }^{* *}$

A discussão a respeito do fenômeno da desindustrialização ${ }^{27}$ e sua ocorrência ou não no Brasil, tem recebido algumas contribuições como o trabalho preparado por Feijó et al. (2005) para o IEDI, o relatório Trade and Development Report, 2003 da UNCTAD, Palma (2005), dentre outros, motivando a continuidade deste debate nesta edição do boletim Economia \& Tecnologia.

Aproveitando este debate, seria propício trazer esta discussão no âmbito da economia paranaense? Afinal, como anda a indústria de transformação neste Estado e qual tem sido a tendência na formação da composição ocupacional nos anos recentes?

Primeiramente cabe ressaltar a problemática de tratar deste tema no âmbito regional, uma vez que a diminuição do emprego na indústria de uma região pode, dentre outros motivos, ser explicada pela realocação de recursos para outras regiões do país em função de deseconomias de aglomeração, por exemplo. Logo, seria inadequado tratar este tema no âmbito de uma das unidades federativas com a mesma abordagem apresentada para esta discussão em nível nacional. Contudo, analisar a dinâmica da composição ocupacional e do valor adicionado no Estado, com atenção especial para a indústria de transformação, tendo esta discussão como pano de fundo pode resultar num exercício interessante.

O processo aqui caracterizado como desindustrialização não é um problema em si uma vez que se trata de um fenômeno observado em diversos países desenvolvidos como resultado natural do ganho de produtividade na indústria. Neste caso, a preocupação seria de que, no Brasil e em outros países da América Latina, esse fenômeno estaria ocorrendo precocemente se comparado aos países ricos, pois no momento em que eles passaram por um

\footnotetext{
* Professor do Departamento de Economia da UFPR. Endereço eletrônico: marciocruz@ufpr.br

** Professor do Departamento de Economia da UFPR. Endereço eletrônico: lucianonakabashi@ig.com.br

27 A evolução normal de uma economia capitalista prevê que durante o estágio de industrialização, a mecanização da agricultura libera mão-de-obra, que é absorvida pela indústria e o setor de serviços. Em uma etapa posterior, a demanda por produtos manufaturados cresce devido ao aumento da renda e a produtividade industrial também, mantendo o nível de emprego nesse setor estável. À medida em que a produtividade das indústrias cresce e o aumento da demanda por seus produtos se torna mais lento, esse setor começa a liberar mão-de-obra para o setor de serviços, onde a produtividade cresce mais lentamente, e a demanda por produtos desse setor começa a crescer a um passo mais constante. $O$ crescimento da demanda por produtos manufaturados cresce muito rapidamente a partir de certo nível de renda, mas depois decresce a partir de um nível mais elevado. Esse processo de transferência de empregos do setor industrial para o de serviços é a desindustrialização que foi experimentada pelas economias maduras de alta renda. (SECEX - UNCTAD)
} 
processo semelhante, mantinham um nível de renda per capita bem mais elevado, conforme demonstram os resultados apresentados por UNCTAD (2003) e Palma (2005).

O Estado do Paraná ainda mantém uma importante participação da atividade agrícola, seja, no valor adicionado da produção ou na composição do emprego. O gráfico abaixo demonstra a participação das três classes de atividades (agropecuária, indústria e serviços) no Estado, entre 1985 e 2003.

Gráfico 1. Participação das classes de atividades no valor adicionado, a preços básicos no Paraná - 1985-2003.

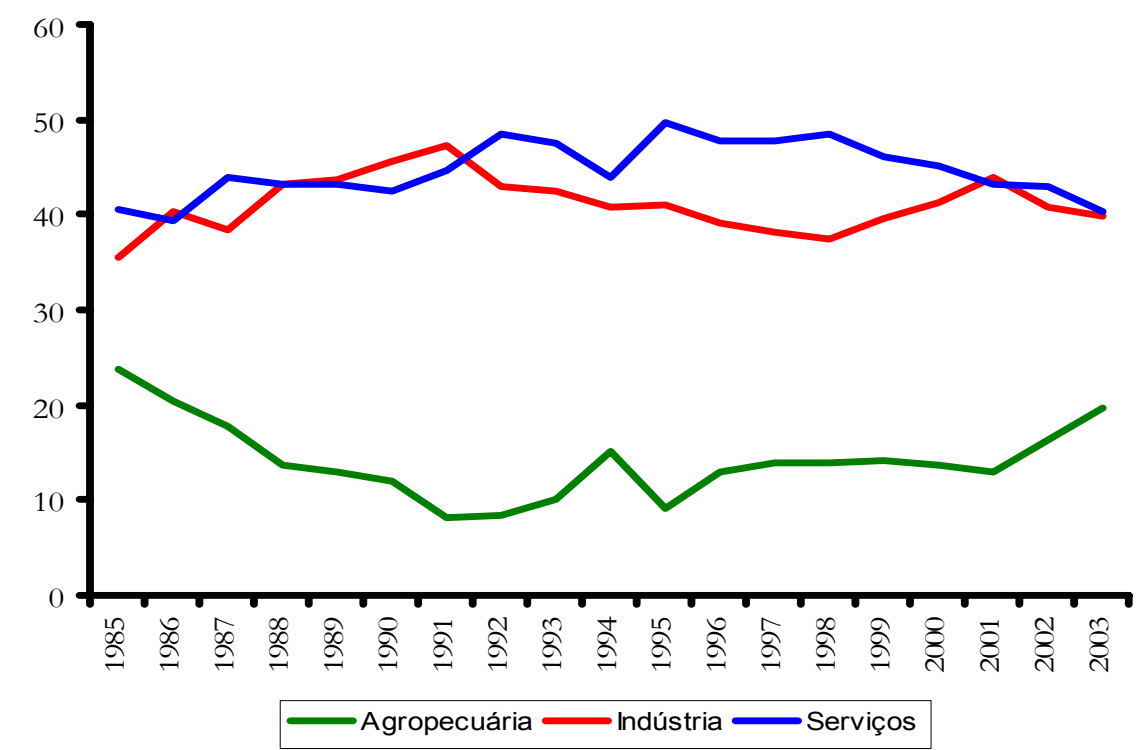

Fonte: IBGE/IPARDES: Contas Regionais.

Observa-se com base no gráfico 1 que a principal mudança fica por conta da perda da representatividade relativa da agropecuária durante a segunda metade da década de 1980, sendo retomada a partir de 2000 e uma queda da indústria ${ }^{28}$ no início dos anos 90 , retomada a partir do final da década. O gráfico 2 apresenta a participação da indústria de transformação no PIB do Paraná e do Brasil. Chama a atenção o fato de que teria havido uma queda bastante expressiva deste segmento a partir de 1990. Seria este desempenho, fruto de um processo de desindustrialização?

28 Cabe ressaltar que houve uma importante mudança estrutural na indústria dos Estado, a qual, conforme pesquisa do IPARDES (2002), resultou no declínio tendencial de atividades tradicionais no Estado, como beneficiamento e desdobramento da madeira, concomitante a inserção de indústrias de maior conteúdo tecnológico. Contudo, este artigo não pretende avançar nesta discussão, recomendando a leitura do documento acima mencionado para os interessados a respeito desse tema.

86 
Gráfico 2. Participação da indústria de transformação no valor adicionado, Brasil e Paraná - 1985-2003.

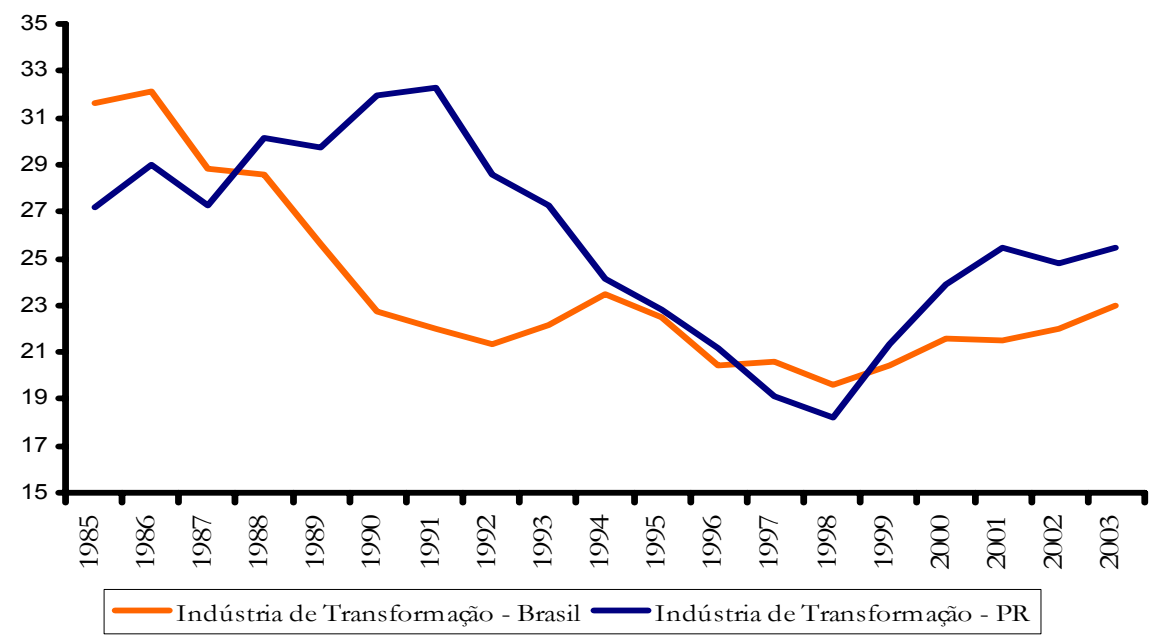

Fonte: IBGE/IPARDES: Contas Regionais.

É importante relembrar que, ao longo da década de 1990, o Brasil passou por dois importantes processos, os quais implicam em conseqüências diretas à indústria, sendo eles: abertura comercial e, na segunda metade da década, controle da taxa de câmbio, a qual manteve-se valorizada até meados de $1999^{29}$.

Neste caso, nota-se que a partir de 1999 a indústria de transformação volta a ter um aumento na participação do PIB, tanto no Paraná, quanto no Brasil, sendo este período caracterizado pela adoção de um regime de câmbio flexível. No caso paranaense, o período pós 1998 também é acompanhado de uma retração da agricultura, o que, junto a um aumento da própria indústria de transformação, explicaria a retomada deste segmento na participação do PIB. Observa-se com base no gráfico 2, que apesar da indústria de transformação paranaense ter passado por uma perda de sua relevância em termos relativo a partir do início da década de 90, esta participação é retomada a partir de 1999, voltando a ter uma representatividade de $25,5 \%$ em 2003 , contra $27,2 \%$ em 1985, o que seria uma variação pouco expressiva para caracterizar parte de um fenômeno de desindustrialização ${ }^{30}$.

Contudo, a participação relativa não permite analisar se a indústria teve, necessariamente, um bom desempenho ou não. Para deixar isso mais claro, o gráfico 3, a seguir, apresenta os dados da Pesquisa Industrial Anual (PIA), demonstrando o desempenho

${ }^{29} \mathrm{Na}$ última edição desta publicação, Moraes (2006, p. 89) apresenta fortes indícios do comportamento da produção industrial do Paraná e a taxa real de câmbio.

${ }^{30}$ A discussão a respeito da desindustrialização no Brasil tem se concentrado na observação do fenômeno a partir da década de 1980. 
do valor da transformação industrial em termos real ${ }^{31}$. Nele, podemos ver o aumento expressivo do valor da transformação industrial no Paraná, em termos reais, a partir de 1999, desempenho este que contou com uma participação importante do aumento da produção de derivados de petróleo, produtos químicos, produtos de madeira e da indústria automobilística.

\section{Gráfico 3. Valor da transformação industrial - Paraná. 1996-2004}

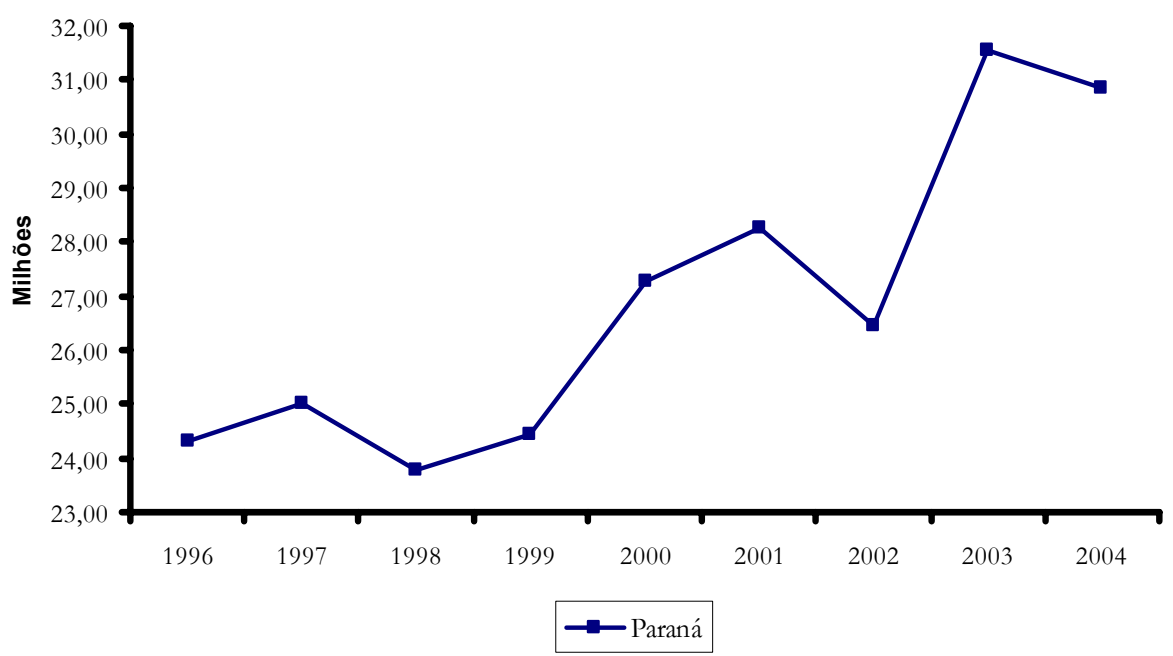

Fonte: PIA/IBGE (2006)

Nota: Preços em R \$ constantes de 2004

Visto que não houve uma perda significativa da indústria de transformação no valor adicionado paranaense, a qual demonstra um desempenho positivo a partir do final da década de 1990, é também importante analisar a participação do setor na composição ocupacional. Neste caso, foram utilizados os dados da Relação Anual de Informação Social (RAIS) e da Pesquisa Nacional de Amostra Domiciliar (PNAD) ${ }^{32}$.

Através das informações disponíveis pela RAIS, apresentadas na tabela 1, observa-se que, apesar de uma leve queda no emprego formal da indústria de 29\%, em 1985, para 27,7\%, em 2004, a participação percentual da indústria de transformação no emprego formal é maior em 2004 do que em 1985 (passou de 21,5\% para 23,8\%). Cabe ressaltar que a ocupação formal na indústria de transformação aumentou 105\% entre 1985 e 2004, enquanto a ocupação total aumentou $85 \%$ no mesmo período.

\footnotetext{
31 O gráfico 3 apresenta os dados da Pesquisa Industrial Anual - PIA, somente a partir de 1996, em função de mudanças metodológicas ocorridas nas pesquisas anteriores.

32 Analisar o comportamento da participação da indústria de transformação na composição ocupacional com base nos dados da PNAD e da RAIS é interessante, uma vez que a primeira capta um comportamento mais amplo, por amostragem, incluindo a atividade informal, enquanto a RAIS apresenta uma amostra mais completa do emprego formal.
} 
Tabela 1. Pessoas ocupadas segundo grupos de atividade no Paraná (1985-2004)

\begin{tabular}{lcccccccccc}
\hline Atividades & $\mathbf{1 9 8 5}$ & $\mathbf{( \% )}$ & $\mathbf{1 9 9 0}$ & $\mathbf{( \% )}$ & $\mathbf{1 9 9 5}$ & $\mathbf{( \% )}$ & $\mathbf{2 0 0 0}$ & $\mathbf{( \% )}$ & $\mathbf{2 0 0 4}$ & $\mathbf{( \% )}$ \\
\hline Agricultura* & 26.145 & 2,4 & 26.899 & 2,2 & 77.221 & 5,3 & 85.616 & 5,2 & 93.162 & 4,6 \\
Indústria & 317.899 & 29,0 & 359.241 & 29,9 & 388.737 & 26,7 & 439.216 & 26,6 & 562.670 & 27,7 \\
$\quad$ Indústria Transf & 235.514 & 21,5 & 268.078 & 22,3 & 301.124 & 20,7 & 353.881 & 21,4 & 483.432 & 23,8 \\
$\quad$ Outras Indústrias & 82.385 & 7,5 & 91.163 & 7,6 & 87.613 & 6,0 & 85.335 & 5,2 & 79.238 & 3,9 \\
Serviços & 753.617 & 68,7 & 813.647 & 67,8 & 987.932 & 68,0 & 1.128 .541 & 68,3 & 1.376 .938 & 67,7 \\
Total & 1.097 .661 & 100 & 1.199 .787 & 100 & 1.453 .890 & 100 & 1.653 .373 & 100 & 2.032 .770 & 100 \\
\hline
\end{tabular}

Fonte: Elaborada própria com base na RAIS/MTE (1985; 1990; 2000; 2004)

* o aumento percentual no emprego relativo a agricultura é parcialmente explicado por uma melhora da pesquisa na captação de informações relativas a esta atividade.

Com relação aos dados da PNAD $^{33}$ (Tabela 2), analisando o período entre 1992 e 2004, observa-se que houve um aumento da participação da indústria de transformação no total de ocupados no Paraná, saindo de 11\% em 1992 para aproximadamente 15\% em 2004. Entretanto, é forte a evidência da menor representatividade do setor agrícola, que representava em torno de 36\% da mão de obra ocupada em 1992 e passa a representar, em 2004, 21\%, sendo esta uma queda expressiva que sinaliza, de fato, a mudança na estrutura produtiva pela qual o Estado passou ao longo da década de 1990.

Tabela 2. Pessoas de 10 anos ou mais de idade, ocupadas na semana de referência, segundo os grupamentos de atividade do trabalho principal no Paraná (1992-2004)

\begin{tabular}{|c|c|c|c|c|c|c|c|c|c|c|}
\hline Atividades & 1992 & $\%$ & 1995 & $\%$ & 1999 & $\%$ & 2001 & $\%$ & 2004 & $\%$ \\
\hline Agrícola & 1.469 .812 & 36,1 & 1.344 .300 & 31,3 & 1.217 .223 & 25,2 & 1.141 .833 & 24,3 & 1.094 .303 & 20,8 \\
\hline Indústria & 741.404 & 18,2 & 826.439 & 19,3 & 969.779 & 20,1 & 931.189 & 19,9 & 1.133 .428 & 21,6 \\
\hline Indústria de Transf & 454.018 & 11,2 & 507.701 & 11,8 & 583.491 & 12,1 & 576.177 & 12,3 & 786.716 & 15,0 \\
\hline Outras Indústrias & 287.386 & 7,1 & 318.738 & 7,4 & 386.288 & 8,0 & 355.012 & 7,6 & 346.712 & 6,6 \\
\hline Serviços & 1.860 .018 & 45,7 & 2.120 .578 & 49,4 & 2.639 .504 & 54,7 & 2.616.957 & 55,8 & 3.021 .233 & 57,6 \\
\hline Total & 4.071 .234 & 100 & 4.291 .317 & 100 & 4.826 .506 & 100 & 4.689.979 & 100 & 5.248 .964 & 100 \\
\hline
\end{tabular}

Fonte: Elaborada própria com base em IBGE / PNAD (1992; 1995; 1999; 2001 e 2004)

Seria interessante trabalhar uma série história mais longa para identificar se esse aumento da participação da indústria de transformação do Paraná seria resultado de uma recuperação após a queda do emprego na produção, mas provavelmente seja resultado da ampliação da relevância da indústria ocorrida na segunda metade da década de 1990. Neste caso, ainda estaríamos seguindo um processo de industrialização crescente no âmbito do Estado do Paraná, sob uma nova dinâmica que se instaurou a partir da segunda metade da década de 90, discutida em IPARDES (2002), com destaque para a consolidação de uma

\footnotetext{
33 As informações referentes à PNAD são a partir de 1992 em função de mudanças da metodologia.
} 
aglomeração produtiva da indústria automobilística e a ampliação da produção dos derivados de petróleo, por parte da Refinaria Presidente Getúlio Vargas (Repar).

Contudo, frente à mudança recente da estrutura produtiva, que ainda mantém na atividade agrícola uma importante representatividade, os dados relativos à composição ocupacional, sugerem que não estaríamos passando por um processo de desindustrialização em nível estadual caracterizado pela dispensa de mão-de-obra para o setor de serviços. Entretanto, nos deparamos com um fenômeno importante quanto à queda do emprego na atividade agrícola, seguida do aumento deste na indústria e no setor de serviços, sendo absorvida, principalmente, por este. Desse modo, caberia uma investigação mais aprofundada para saber que tipo de serviços estaria tendo maior representatividade, uma vez que estão englobados, nesse mesmo contexto, atividades bastante heterogêneas como, por exemplo, a indústria de software e o comércio ambulante.

Este artigo buscou analisar se a indústria de transformação no Estado do Paraná estaria sinalizando para um comportamento convergente ao do fenômeno caracterizado como desindustrialização precoce, o qual, segundo o relatório da UNCTAD (2003), estaria passando alguns países da América Latina. A análise sugere que esse setor apresentou uma queda da importância relativa no Paraná no início da década de 1990, entretanto, teria passado por um processo de mudança da sua estrutura produtiva, ressaltando dois fenômenos importantes deste: recuperação de sua participação no valor adicionado, a partir de 1999, que foi coincidente com a desvalorização e mudança no regime cambial; aumento da participação do setor na composição ocupacional, de acordo com os dados da PNAD, indicando que a indústria paranaense ainda se encontra em expansão e absorvendo mão de obra do setor agrícola. Desta forma, os resultados do Paraná não demonstram uma convergência com o fenômeno constatado em nível nacional, o que pode ser parcialmente explicado por um processo de desconcentração industrial ocorrido no Brasil, ao longo dos anos $90^{34}$ ou mesmo por um processo de industrialização tardio. Dentre as questões importantes que surgem com este tema e devem ser retomadas, ressalta-se uma análise setorial da indústria de transformação, buscando identificar de forma mais detalhada as atividades que respondem pela recuperação deste setor no Paraná, a partir de 1999, identificando as atividades que cresceram e aquelas que apresentaram perdas, buscando traçar uma discussão conjuntural, uma vez que o Estado tem apresentado sinais de queda na atividade industrial.

${ }^{34}$ Maiores detalhes a respeito deste processo, ver LOURENÇO (1995a; 1995b).

90

Economia \& Tecnologia - Ano 02, Vol. 05 - Abr./Jun. de 2006 


\section{Referências Bibliográficas}

FEIJÓ, C. A. CARVALHO, P.G.M; ALMEIDA, J.S.G. (2005). Ocorreu uma desindustrialização no Brasil? Texto de Discussão - Instituto de Estudos para o Desenvolvimento Industrial. Disponível em: http://www.iedi.org.br, em 10 de junho de 2006.

IBGE (2006). Pesquisa Industrial Anual. Disponível em: http://www.ibge.gov.br, 20 jun.2006.

IPARDES (2002). Crescimento, reestruturação e competitividade industrial no Paraná - 1985-2000. Instituto Paranaense de Desenvolvimento Econômico e Social. Curitiba: IPARDES, 2002. $84 \mathrm{p}$.

LOURENÇO, G. M (2005a). A desconcentração industrial e o Paraná. In: Análise Conjuntural. Curitiba: IPARDES, v. 27, n. 5-6, maio/jun. 2005, (p. 17-18).

LOURENÇO, G. M. (2005b) Economia paranaense: rótulos históricos e encaixe recente na dinâmica brasileira. In: Análise Conjuntural. Curitiba: IPARDES, v. 27, n. 11-12, nov./dez. 2005, (p. 8-14)

MORAES, G. I (2006). Economia Paranaense: Sobre juros, câmbio e outros problemas. In: Economia \& Tecnologia, ano 2, vol. 4, jan./mar. de 2006, p. 87-92.

PALMA, G. (2005). Quatro fontes de "desindustrialização" e um novo conceito de "doença holandesa". Conferência de Industrialização, Desindustrialização e Desenvolvimento, FIESP e IEDI, , 28 de Ago. 2005. Disponível em http://www.fiesp.org.br, em 10 de junho de 2006.

UNCTAD. Trade and Development Report, 2003. Disponível em: http:// www.unctad.org, em 10 de junho de 2006. 
